
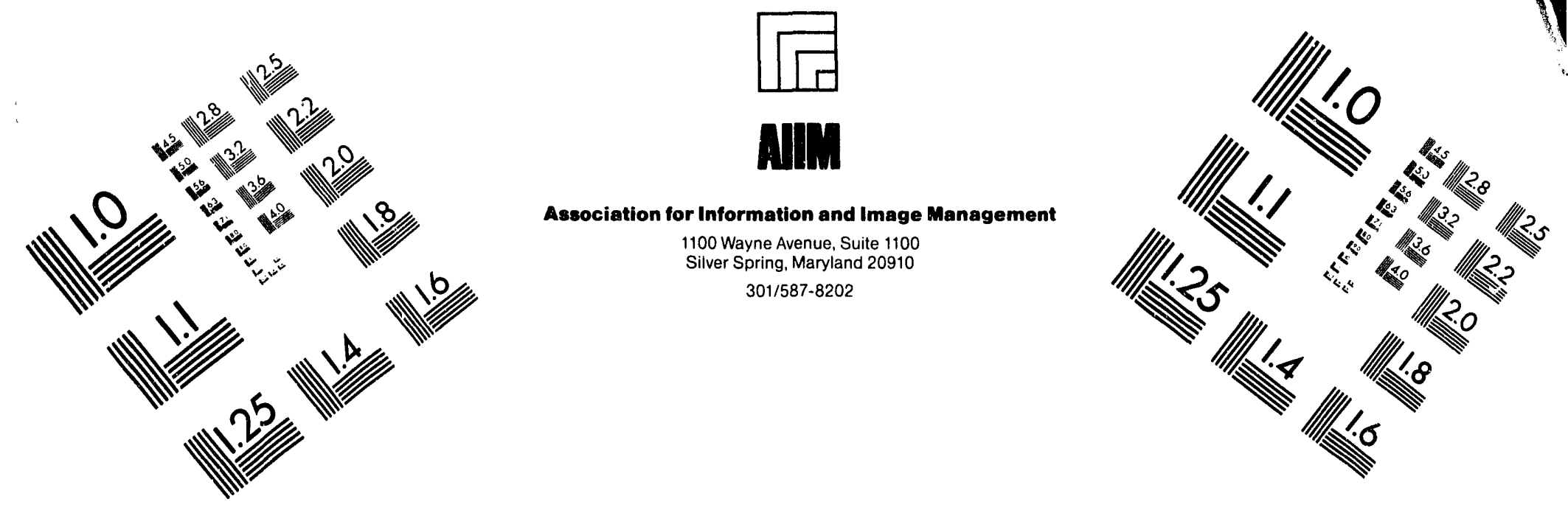

Centimeter

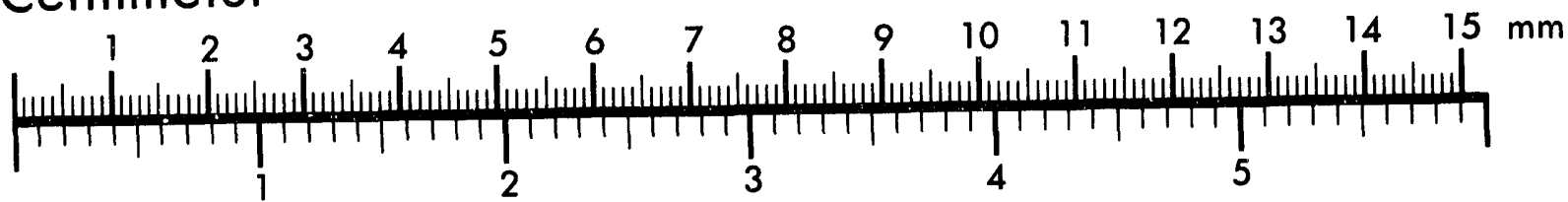
Inches
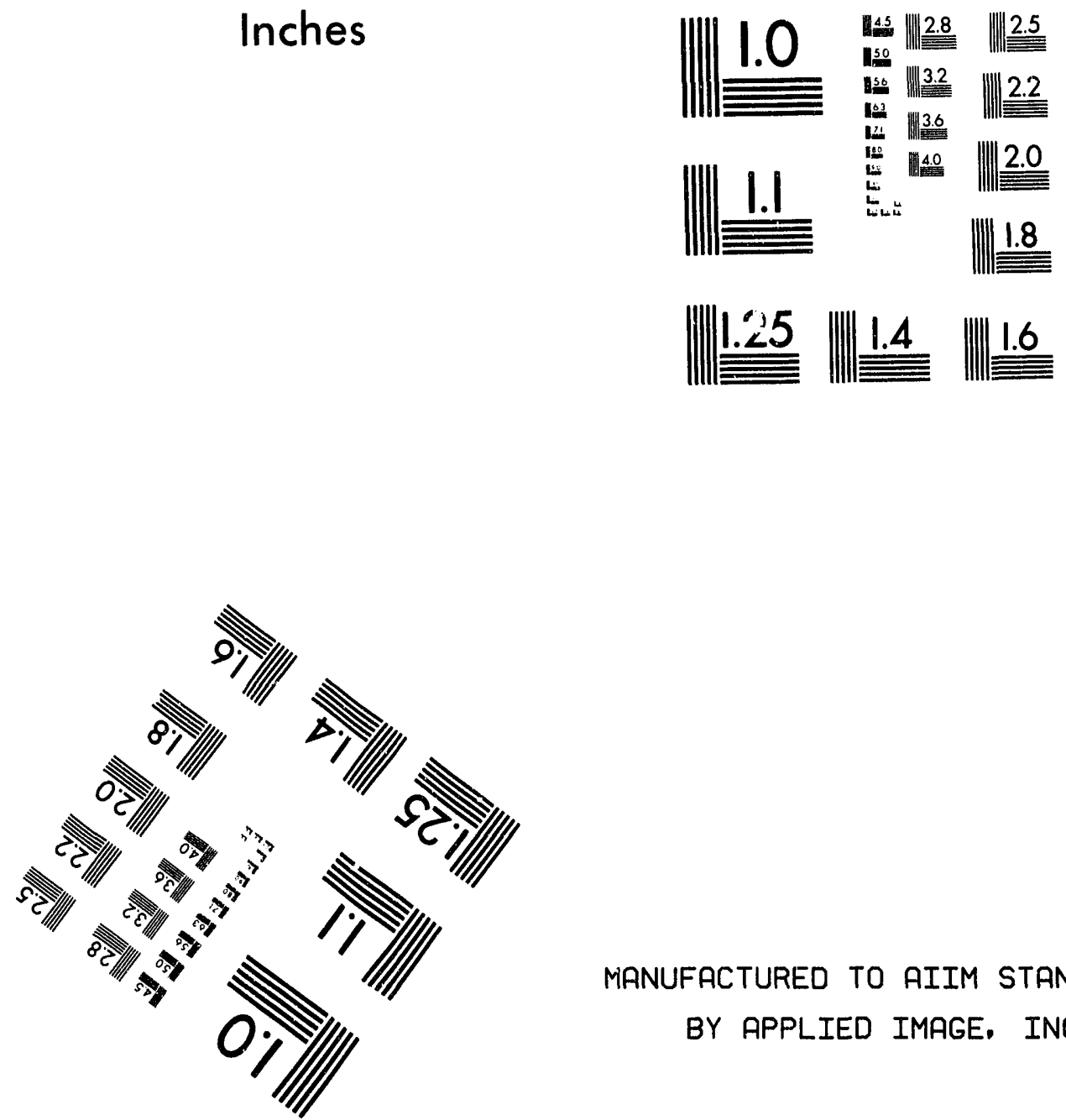

MANUFACTURED TO AIIM STANDARDS

BY APPLIED IMAGE, INC.

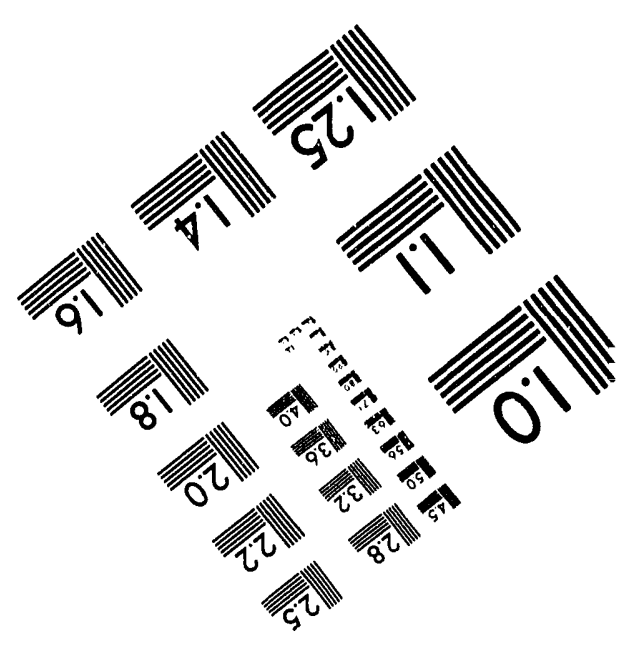



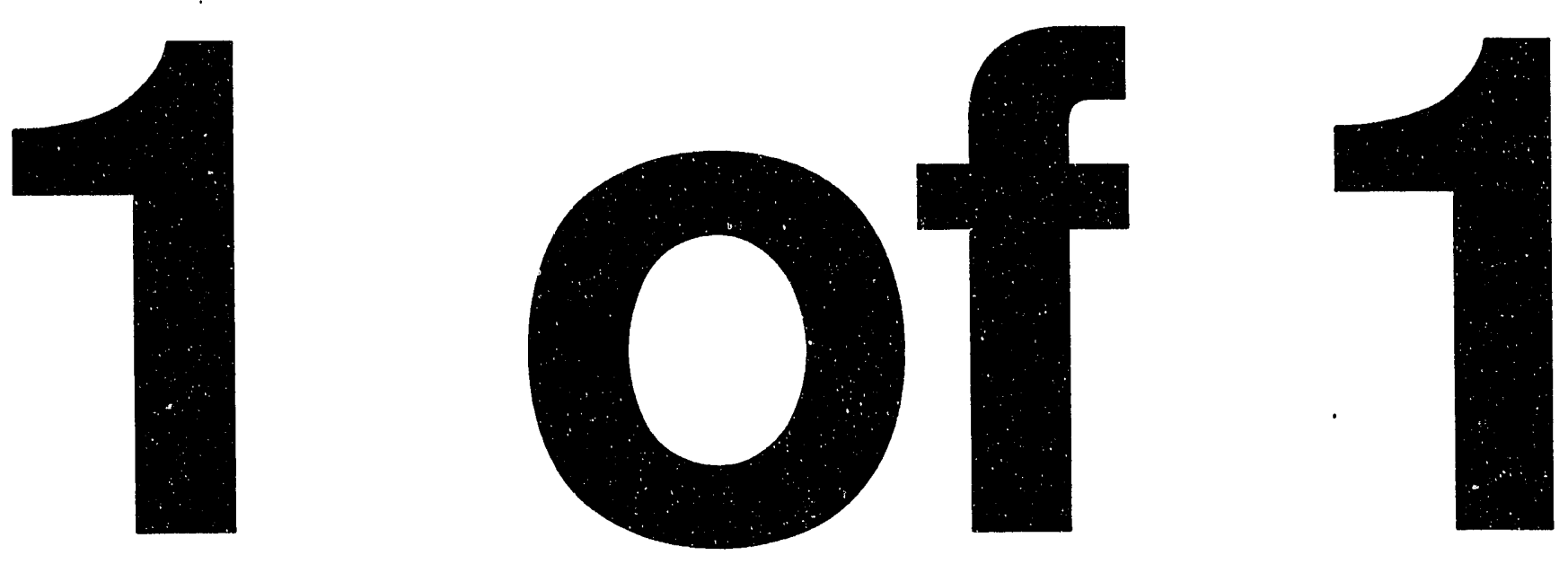
Electron Beam Emittance Monitor for the SSC

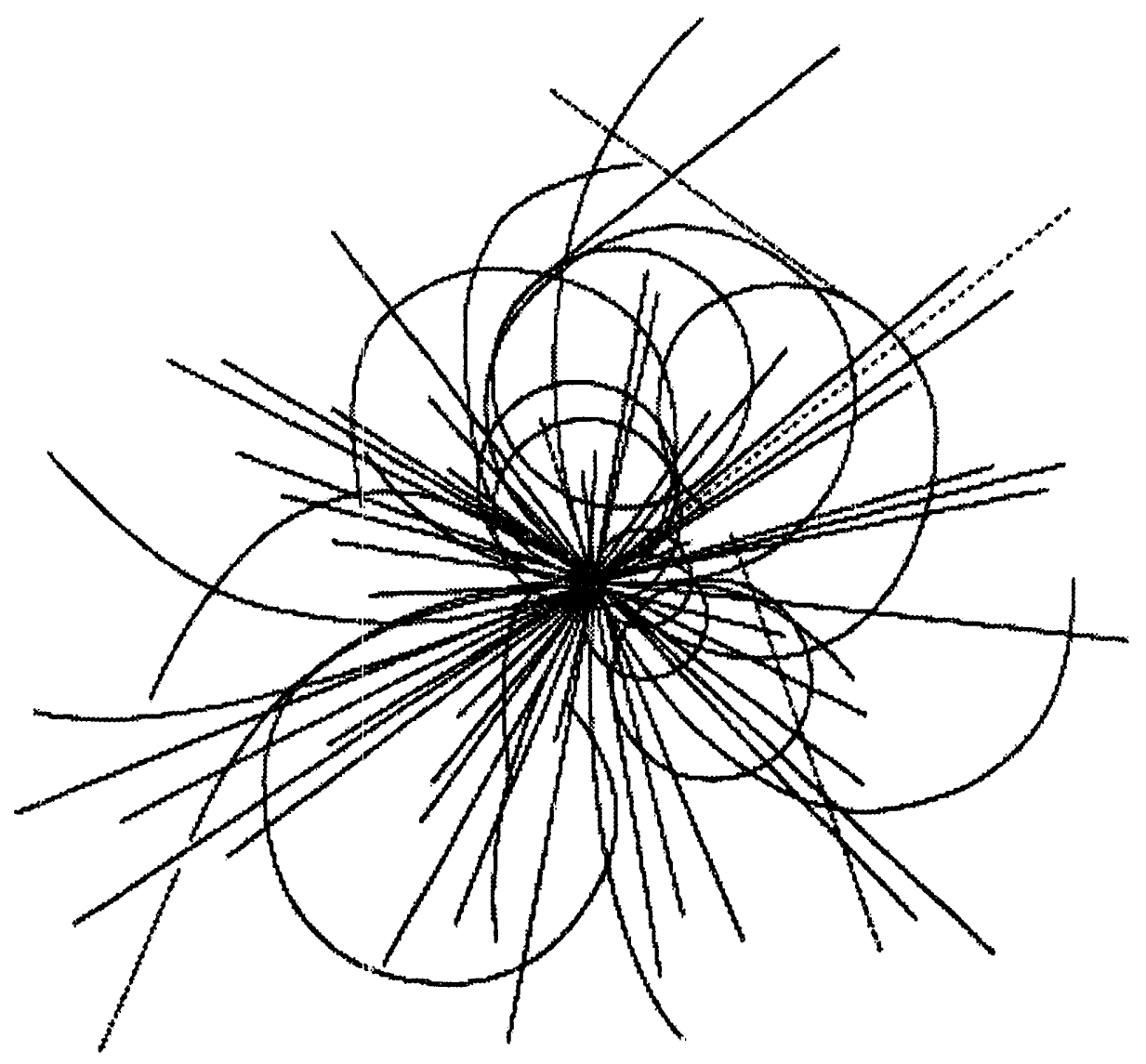

\section{Superconducting Super Collider Laboratory}

E. Tsyganov

R. Meinke

W. Nexsen

S. Kauffmann $: C E I V E D$

A. Zinchenkd

A. Taratin JUN 011993

OSTI 


\section{Disclaimer Notice}

This report was prepared as an eccount of work sponsored by an agency of the United States Govemment. Noither the United States Govemment or any agency thereof, nor any of their employeses, makes any warranty, express or implied, or assumes any legal liablity or responsibility for the eccuracy, completeness, or usefulness of any information, apparatus, product, of process disclosed, or represents that its use would not infringe privately owned rights. Reterence herein to any spectic commercial product, process, or service by trade name, trademark, manutacturer, or otherwise, does not necessarily constitute or imply its endoreement, recommendation, or favoring by the United States Government or any agency thereof. The viows and opinions of authors expressed herein do not necessarily state or reftect those of the United States Govemment or any apency thereof.

Superconducting Super Collider Laboratory is an equal opportunity employer. 


\title{
Electron Beam Emittance Monitor for the SSC
}

\author{
E. Tsyganov, R. Meinke, W. Nexsen,
}

S. Kauffmann, A. Zinchenko, and A. Taratin .

Superconducting Super Collider Laboratory ${ }^{\dagger}$

2550 Beckleymeade Ave.

Dallas, TX 75237

May 1993

"To be presented at the 1993 IEEE Particle Accelerator Conference on May 17-20, Washington, D.C. tOperated by the Universities Research Association, Inc., for the U.S. Department of Energy under Contract No. DE-AC35-89ER40486. 


\title{
Electron Beam Emittance Monitor for the SSC
}

\author{
E. Tsyganov, R. Meinke, W. Nexsen, S. Kauffmann, A. Zinchenko, and A. Taratin \\ Superconducting Super Collider Laboratory* \\ 2550 Beckleymeade Ave., Dallas, TX 75237 USA
}

\section{Abstract}

A nondestructive beam profile monitor for the Superconducting Super Collider (SSC) is presented using as a probe a low-energy electron beam interacting with the proton bunch charge. Results using a full Monte Carlo simulation code look promising for the transverse and longitudinal beam profile measurements.

Recently a low-energy electron beam was proposed [1] for nonperturbing diagnostics of high-energy electron beams, based on earlier works $[2,3]$. We studied a similar approach in connection with applications for the SSC collider and its transfer lines.

A diagram of the beam emittance monitor for the SSC using a low-energy probe electron beam is presented in Figure 1. A strobed electron gun directs the beam of $10-\mathrm{KeV}$ electrons perpendicular to the proton beam. Deflected electrons are detected with a position sensitive detector. A silicon microstrip detector seems to be a perfect candidate for this. The monitor can use a well-focused electron beam sweeping through the proton beam, or a wide, parallel electron beam. Single bunch measurements are possible in the latter case, i.e., when illuminating a bunch of high-energy particles by a wide parallel electron beam one can obtain a specific "shadow picture" of the proton bunch. The duration of the pulse of electrons in this case should be shorter than the duration of the proton bunch.

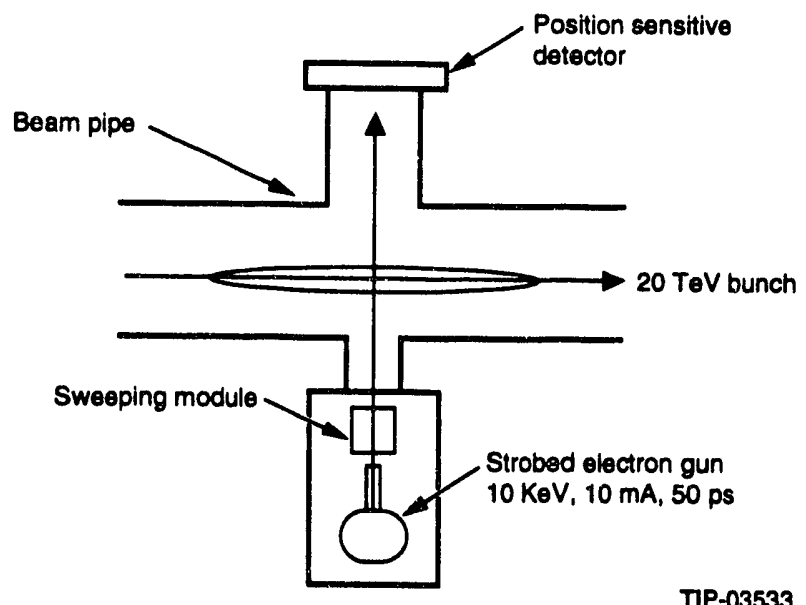

Figure 1. Electron beam profile monitor for the SSC collider.

*Operated by the Universities Research Association, Inc., for the U.S. Department of Energy under Contract No. DE. AC35-89ER40486.
We used the ZBEAM simulation code described elsewhere $[4,5]$ to trace probe electrons in the vicinity of a $20-\mathrm{TeV}$ beam. Electrons were traced from $Y=-1 \mathrm{~cm}$ to $Y=2 \mathrm{~cm}, Y$ is being the direction of the electron beam. The $Z$-direction corresponds to the direction of a proton beam. Deflection angles of electrons in the $X-Y$ plane were calculated versus the probe beam position along the $\mathrm{X}$-direction.

The bunch structure of the $20-\mathrm{TeV}$ beam was taken into account. The bunch was considered as a moving charge equivalent to the charge of $10^{10}$ protons with three-dimensional Gaussian distribution in space. A Gaussian distribution with sigma equal to $5 \mathrm{~cm}$ was used in the Z-direction. Four beam sizes were considered with sigmaX $=$ sigmaY, for sigma being equal to $50 \mu \mathrm{m}, 100 \mu \mathrm{m}, 200 \mu \mathrm{m}$ and $500 \mu \mathrm{m}$. The electrons were exactly synchronized with the proton bunch. In our case the Z-component of the electrical field of the bunch is rather small, and we neglect it.

It was found that the electron deflection angle is quite sensitive to the position of the electron beam inside the proton bunch. Figure 2 presents the scattering angle of the electron versus its distance from the center of proton beam (impact parameter) for different beam sizes. By measuring the deflection of the electron beam, it is possible to obtain the rms size of the beam with good precision. The probing electron beam would be swept across the main beam to obtain a full deflection profile. Electrons should be focused in the plane of the proton beam in a spot less than $10 \mu \mathrm{m}$ in size in order to not introduce any significant broadening to the measured beam size. Figure 3 demonstrates the sensitivity of the method to the shape of the charge distribution inside the bunch. Scattering angles versus impact parameter are presented for Gaussian and uniform charge distributions in the $X-Y$ plane with the same $r \mathrm{~ms}, 50 \mu \mathrm{m}$. In the Z-direction both distributions are Gaussian with sigma of $5 \mathrm{~cm}$. An obvious difference between the two curves is seen.

A notable, and not entirely intuitive, feature of Figures 2 and 3 is the leveling off of the deflection angle for values of the impact parameter which exceed the X-extent of the beam. If the impact parameter $b$ is beyond the X-extent of the beam, but still very small compared to the $Z$-extent of the bunch, it is reasonable to model the force felt by the probe electron as that due to an infinite line charge,

$$
\overrightarrow{\mathrm{F}}(\overrightarrow{\mathrm{R}})=\frac{-2 e q_{2} \overrightarrow{\mathrm{R}}}{|\overrightarrow{\mathbf{R}}|^{2}}
$$

where $e$ is electron's charge, $q_{L}$ is the linear charge density of the idealized line charge, and $\vec{R}$ is the two-dimensional vector $(\mathrm{X}, \mathrm{Y})$. Thus, after some calculations, we arrive to 


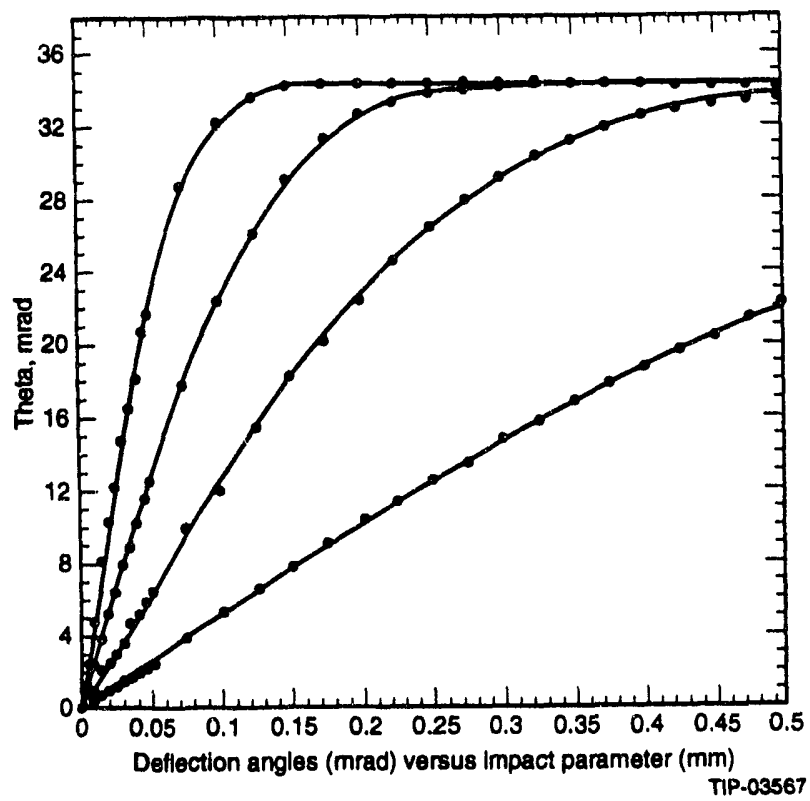

Figure 2. Deflection angles versus electron beam positions relative to the center of a proton bunch. Data for three-dimensional Gaussian distributions of the bunch charge with sigmaX $=$ sigmaY equal to $50 \mu \mathrm{m}, 100 \mu \mathrm{m}$, $200 \mu \mathrm{m}$ and $500 \mu \mathrm{m}$. SigmaZ is equal to $5 \mathrm{~cm}$. Smooth curves represent a fit of data by error function.

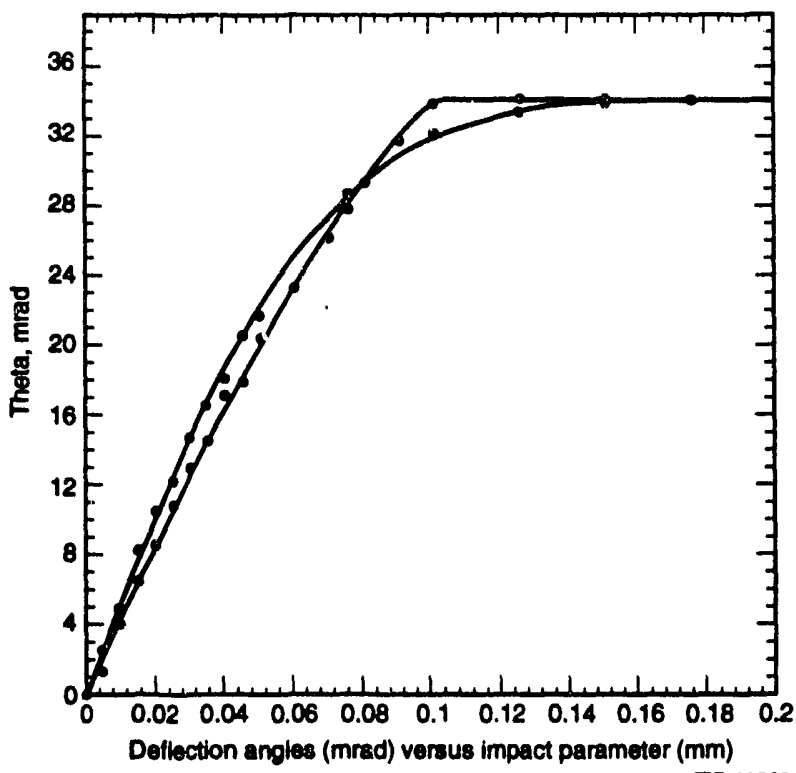

Figure 3. Scattering angle vs. impact parameter for two charge distributions with the same rms, $50 \mu \mathrm{m}$. Upper curve-uniform distribution of charge within a $100 \mu \mathrm{m}$ radius of beam, lower curve-Gaussian distribution with sigma $50 \mu \mathrm{m}$. A difference between the two curves is seen.

$$
\frac{d \theta}{d b}=\frac{-4 \pi e}{m \gamma \mathrm{v}^{2}} \int_{-\infty}^{\infty} d \mathrm{Y} \varrho_{L}(b, \mathrm{Y})
$$

In other words, the derivative of the deflection angle as a function of impact parameter is proportional to the Y-integrated profile of the transverse beam charge distribution $\varrho_{L}$. This happens to be precisely the same information as one obtains from a probe wire ("flying wire") which is passed perpendicular to the beam in the Y-direction (that of the probe electron) through the $\mathrm{X}$-point corresponding to that electron's impact parameter $b$. The deflection functions shown in Figure 2, then, simply proportional to the indefinite $b$-integrals of the very "beam profiles" which are measured by "flying wires"!

Figure 4 presents the dependence of the X-position of a deflected electron at $Y=2 \mathrm{~cm}$ versus its initial $X$-position at $Y=$ $-1 \mathrm{~cm}$. Electrons are "switched" in the X-direction by the proton bunch charge around the center of the proton beam, and the shape of this switching is defined by the proton beam profile. Note, that the shape of the curve presented defines not only the transverse shape of the proton beam, but also the longitudinal charge density at the center of the bunch.

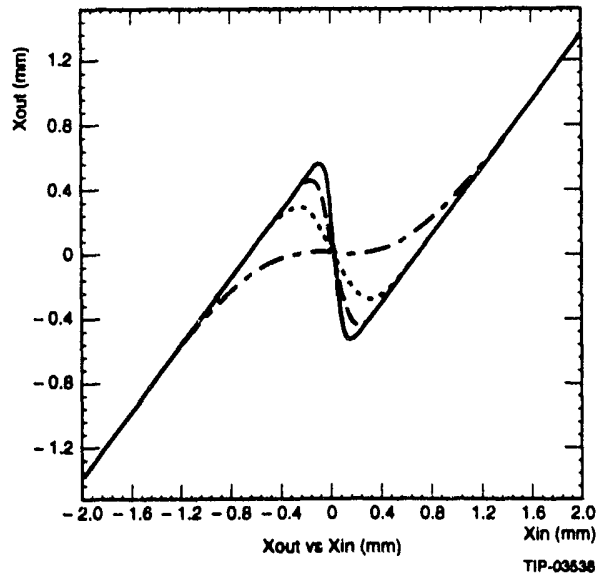

Figure 4. X-position of an electron at the plane $Y=2 \mathrm{~cm}$ versus its $X$-position at the plane $Y=-1 \mathrm{~cm}$. Solid line is for Gaussian beam with sigmaX $=$ sigma $Y=50 \mu \mathrm{m}$, dashed line-for $100 \mu \mathrm{m}$, dotted line-for $200 \mu \mathrm{m}$, dash-dotted line-for $500 \mu \mathrm{m}$.

Figure 5 presents the $\mathrm{X}$-profiles of a 4-mm wide, parallel, uniformly distributed, electron beam at the $Y=2 \mathrm{~cm}$ plane for different proton beam sizes. In the Z-direction this beam could be as wide as $10 \mathrm{~mm} .10^{6}$ electrons were simulated for each distribution. It is easy to see that the shape of the electron beam profile resulting from interaction with the proton beam is very sensitive to the size of the proton beam. Similar data, but with a Gaussian angular divergence for the electron beam of $1 \mathrm{mrad}$, are presented in Figure 6. Sensitivity of the resulting electron beam profile to the size of the proton beam remains adequate.

In conclusion, the preliminary calculations presented here show that the emittance of a $20-\mathrm{TeV}$ beam at the SSC can be effectively monitored with low energy electron beams in a 
non-destructive technique. Further detailed studies of the process are needed, including construction of a prototype of the device and testing its performance on high energy beams.
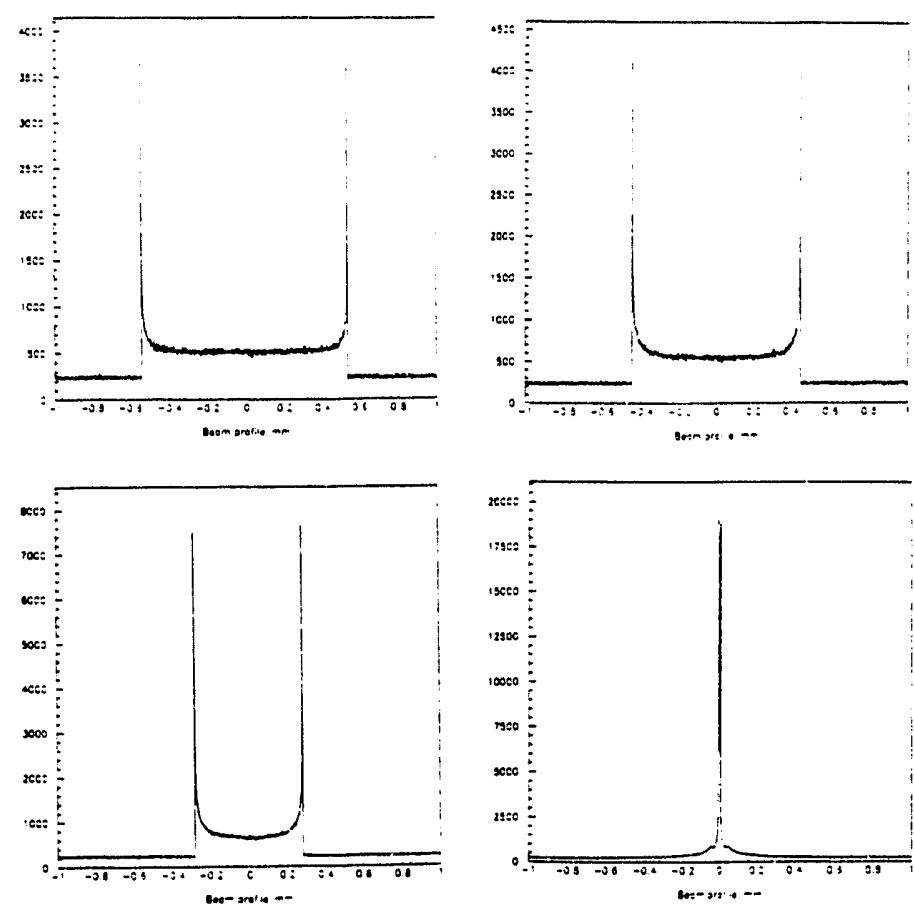

Figure 5. Electron beam profiles at the plane $Y=2 \mathrm{~cm}$ for different proton beam sizes. Upper left-for sigma $50 \mu \mathrm{m}$, upper right-for sigma $100 \mu \mathrm{m}$, lower left-for sigma $200 \mu \mathrm{m}$, lower right-for sigma $500 \mu \mathrm{m}$. Uniform distribution of the electron beam from $-2 \mathrm{~mm}$ to $+2 \mathrm{~mm}$ with no angular divergence is assumed at the plane $\mathrm{Y}=$ $-1 \mathrm{~cm} .10^{6}$ electrons are used.
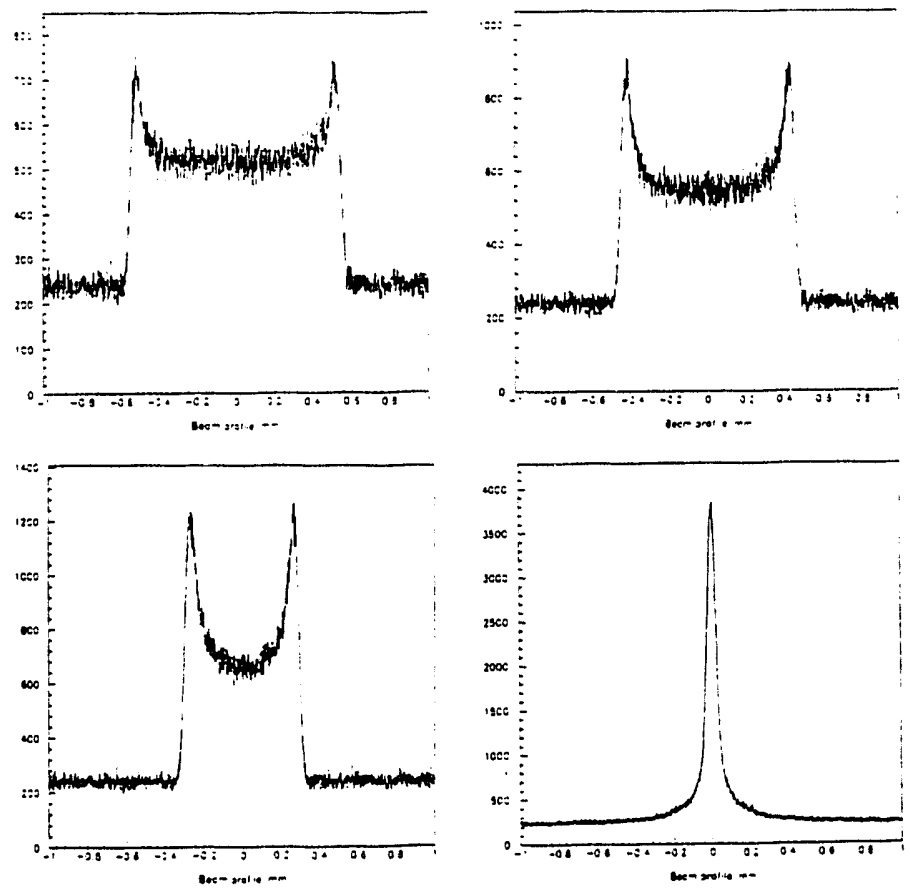

Figure 6. The same, as in Figure 5, but a Gaussian divergence with sigma of $1 \mathrm{mrad}$ is used for the primary electron beam.

\section{REFERENCES}

V. Shestak et al., "An Electron Beam Probe for Ion Beam Diagnosis," TRIUMF Design Note, TRI-DN-87-36 Rev, (1987). J. Pasour and M. Ngo, "Nonperturbing Electron Beam Probe to Diagnose Charged-Particle Beams," Rev. Sci. Instrum. 63 (1992) 3027.

[2] P. D. Goldan, Phys. Fluids, 13 (1970) 1055.

[3] D. A. Swanson, B. E. Cherrington, and J. T. Verdeyen, Phys. Fluids, 16 (1973) 1939.

[4] A. Maschke, W. Nexsen, E. Tsyganov, A. Taratin, A. Zinchenko, "Angular Divergence of $10 \mathrm{KeV} \mathrm{Art}$ and CS+ Ions Due to Ion-Bunch Interaction," Internal Note of the SSCL Collider Group.

[5] R. Meinke, W. Nexsen, E. Tsyganov, A. Zinchenko, "Limitations of the Residual Gas Ionization Beam Profile Monitor for the SSC Collider," SSCL-602, November 1992. 

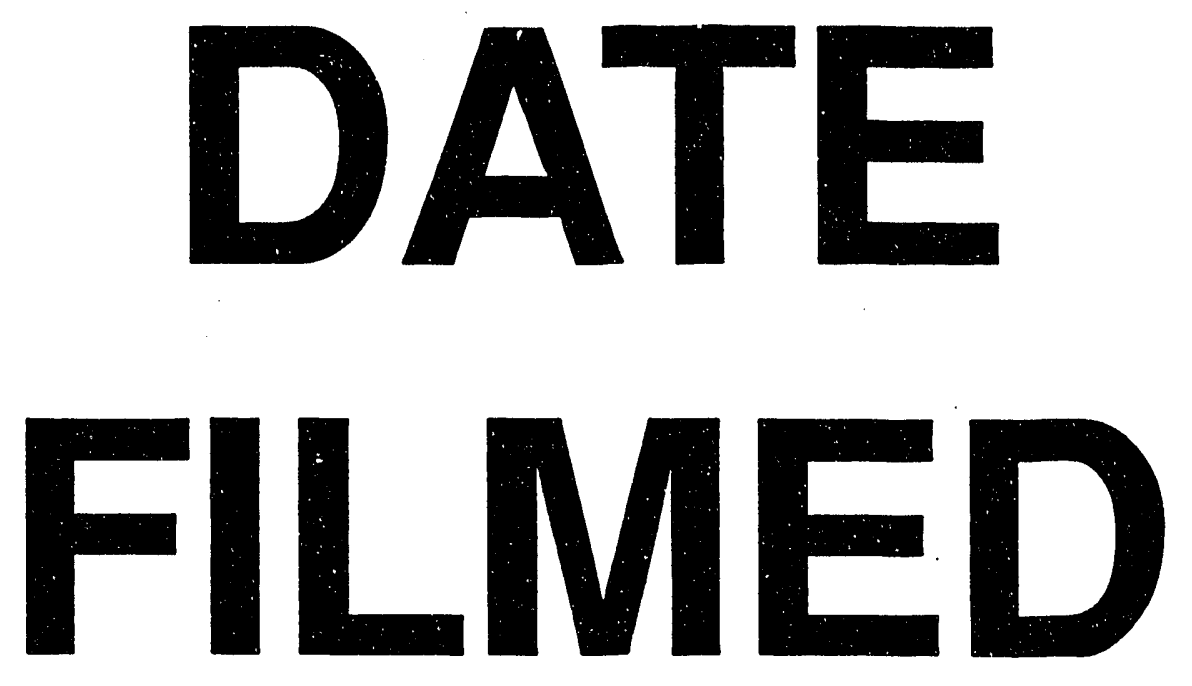

$8 / 13 / 93$
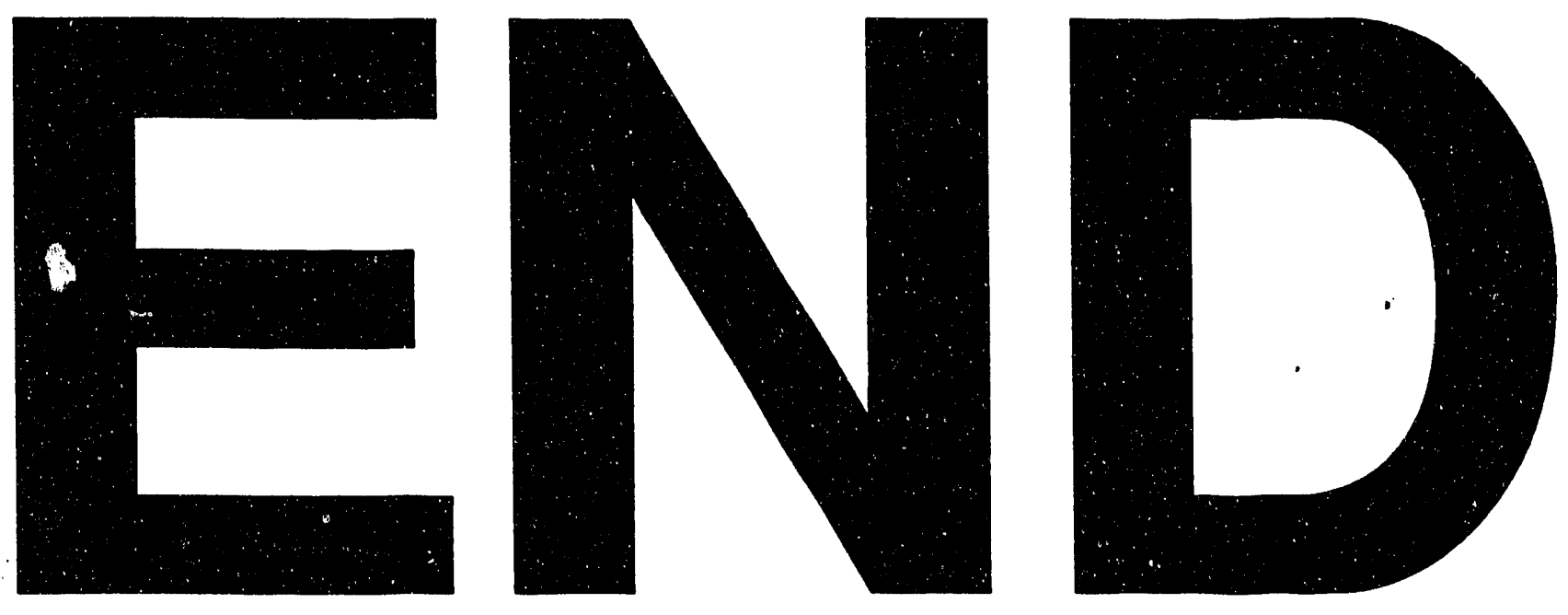
